\title{
Altruism or Self-Interest? Exploring the Motivations of Open Access Authors
}

\author{
Robert Heaton, Dylan Burns, and Becky Thoms
}

\begin{abstract}
More than 250 authors at Utah State University published an Open Access (OA) article in 2016. Analysis of survey results and publication data from Scopus suggests that the following factors led authors to choose OA venues: ability to pay publishing charges, disciplinary colleagues' positive attitudes toward OA, and personal feelings such as altruism and desire to reach a wide audience. Tenure status was not an apparent factor. This article adds to the body of literature on author motivations and can inform library outreach and marketing efforts, the creation of new publishing models, and the conversation about the larger scholarly publishing landscape.
\end{abstract}

\section{Introduction}

Advocacy for Open Access (OA) is one of the cornerstones of contemporary librarianship. A common definition of $\mathrm{OA}$ is "the free, immediate, online availability of research articles coupled with the rights to use these articles fully in the digital environment."1 ${ }^{1}$ This definition more precisely applies to so-called "Gold Open Access," which is just one of many models in a complex OA-publishing ecosystem. This study, focusing on Gold OA, explores the complex factors that motivate each of the stakeholders in that ecosystem. It may be accurate (though incomplete) to assume that publishers seek profit, libraries seek to expend limited funds efficiently, and authors seek the widest possible readership. Crucially, these self-centered motivators may not be mutually exclusive of more altruistic factors. Librarians have long explored the value of OA and encouraged their patrons to publish research results openly, but academic librarians know very little about what motivates authors to publish OA. Where librarians often strongly favor the ethics of open publishing, this position may prove unpersuasive to detractors of OA. No single OA model can address all the needs of each stakeholder, but, in creating and promoting avenues for OA, libraries should understand and acknowledge those needs.

Despite the financial costs and the sometimes contentious and politicized nature of OA publishing, many university faculty members still choose it. Why? Unfortunately, because authors make a limited appearance in the literature on OA stakeholders, librarians often work from anecdotes and assumptions. We all know faculty who advocate strongly for open publishing, and altruism resonates with many faculty authors when librarians bring it up. On the other hand, the pressures of tenure and promotion are a well-documented feature of scholarly

\footnotetext{
${ }^{*}$ Robert Heaton is Collection Management Librarian, Dylan Burns is Digital Scholarship Librarian, and Becky Thoms is Head of Digital Initiatives, all at Utah State University Libraries; email: robert.heaton@usu.edu, dylan. burns@usu.edu,becky.thoms@usu.edu. (C2019 Robert Heaton, Dylan Burns, and Becky Thoms, AttributionNonCommercial (http://creativecommons.org/licenses/by-nc/4.0/) CC BY-NC.
} 
communication, and those same pressures might logically influence authors to choose OA (or not to). Faculty members also feel considerable influence from peers and others in their professional spheres and take cues from them in deciding where and how to publish. Librarians simply do not know which factors most strongly compel researchers to choose OA. To address this gap in the literature, this article investigates the degree to which such factors as tenure status, discipline, funding availability, the opinions of colleagues, and personal beliefs motivated Utah State University (USU) authors who chose to publish an OA article. The findings have implications for libraries' support of such OA publishing initiatives as institutional OA funds, OA policies, and open repositories.

\section{Literature Review}

Much discussion on the concept of OA takes place in the scholarly communication and academic communities, where they generate definitions of it, models for enacting it, proposals for its long-term sustainability, and an abundance of strongly held opinions regarding its value. As one prominent example, although the blog The Scholarly Kitchen aims "[ $t$ ]o advance scholarly publishing" in general, ${ }^{2}$ roughly half of its posts deal either directly or indirectly with OA. Unfortunately, in spite of the avalanche of information from the fields of publishing and librarianship, much less is known about the perspectives of authors in the various disciplines, from science and engineering to arts and humanities. As this literature review will show, research tentatively suggests that finances, field of study, and personal benefits (including tenure incentives) may motivate OA authors.

First, authors' understandable sensitivity to high publishing costs has led many organizations to create formal funding-support mechanisms. A multitude of articles delve into the various financial angles of OA publishing, including article processing charges (APCs, the payment from the author to make articles OA), ${ }^{3}$ Hybrid OA models (where the publisher collects subscription fees and authors of an individual article can make it OA by paying an APC), ${ }^{4}$ and library-or institution-sponsored OA funds. ${ }^{5}$ The Scholarly Publishing and Academic Resources Coalition's (SPARC) annual report, OA Funds in Action, clearly demonstrates the growth and success of campus OA funds. More than 3,000 authors from 51 institutions provided such a fund according to the 2017 report, demonstrating those institutions' support for the concept of OA publishing. ${ }^{6}$ Conversely, writing in College $\mathcal{E}$ Undergraduate Libraries in 2014, Monson, Highby, and Rathe noted that a shortage of funds to pay APCs was a deterrent for faculty considering OA publishing. ${ }^{7}$ Björk and Solomon concluded that, while "many authors have been sensitive to the price level," they found that such factors as higher quality and greater likely citation outweighed cost in authors' minds. ${ }^{8}$ Greater likelihood of being cited has clear ties to the goals of promotion and tenure, which could lend it special weight to help authors overcome their sensitivity to OA prices.

Although financial support often resolves authors' economic concerns about OA, in some fields of study, broad disciplinary attitudes toward OA seem to influence the perceptions of individual authors. Despite widely held assumptions that researchers in the sciences generally, and the health sciences specifically, are more accepting of OA, one study indicated that health sciences faculty at one institution in fact supported the (non-OA) status quo in scholarly publishing. ${ }^{9}$ Another study showed that OA authors' perceptions can differ from those of their colleagues, even in the same discipline. For example, the altruistic goals of "Free Access" and "Audience Accessibility" most frequently motivated biomedical authors at the 
University of North Carolina and Duke University. ${ }^{10}$ A third study also explored biomedical publishing and found that, instead of discipline, a major source of differences in OA uptake was the authors' "past knowledge-disclosure practices," such as in commercial patents versus open-source software. ${ }^{11}$ Our study hoped to clarify both the prevalence of the various motives for OA authors and the extent of disciplinary differences.

Along with discipline, tenure status contributes to the complexity of understanding author attitudes toward publishing in OA venues and publishing in general. Higher education research has been interested in evaluating where, how, and why authors choose to publish for as long as tenure or hiring committees have existed. Seventy-one percent of respondents to a survey on tenure standards rated research as the most important factor for tenure. ${ }^{12}$ Yet higher education research is deeply conflicted on whether promotion-and-tenure incentives, researchers' own interests, or both influence researchers to publish. One study found that faculty who "valued promotion" published peer-reviewed articles more often than those who placed "less importance on promotion." ${ }^{13}$ A contrasting study found that full professors, those without rank incentives, were often the most prolific authors at universities, which suggests that some researchers ascribe a deeper value to publishing beyond the promotional rewards. ${ }^{14}$ Instead, "peer recognition, pure enjoyment, [and] a continuing dedication to search for truths... continue to operate during the full professorship for some, even if not for all."15 If tenure and promotion have any sway on authors' publishing practices, it is notable that some researchers increasingly speculate that the number of publications matters less than the impact, readership, and alternative metrics related to publications. ${ }^{16}$

As academic publishing moves more fully online, OA may become more attractive to authors in general. While some may expect younger faculty to embrace the emergent values of OA publishing more fully than others do, faculty at all tenure levels show support for OA. ${ }^{17}$ During the past decade, journals across disciplines have complicated the publishing picture with editorials that have such titles as "It Is Time to Replace Publish or Perish with Get Visible or Vanish."18 As an example of this growing focus on researchers' online profiles, British Journal of Sports Medicine editors comment that the "300-year-old tradition" of scholarly publishing, of producing and then disseminating research, ignores the reception of research, a concept the editors term "knowledge translation." In this domain, they claim, digital publishing, social media, and OA can bridge the gaps between completed research and readers. ${ }^{19}$ Educational Gerontology editor Nieli Langer explains that, while it is tempting for institutions to count "the number of articles academics publish [as] a measure of the quality of the individuals," such as through $\mathrm{H}$-factors or number of citations, this approach can "neglec[t] to weight the academic contributions of the articles published." ${ }^{20}$ Authors achieve these veritable "academic contributions" as readers discover and use their work. This renewed focus on visibility could lead to an increased reliance on the online publishing and sharing of content and, possibly, OA publishing.

Proponents of OA frequently emphasize the unique impact of OA publications on an article's readership and citation count. Although some still debate the magnitude of such an effect, researchers generally acknowledge its existence. Concrete numbers come from SPARC Europe (a branch of the global Scholarly Publishing and Academic Resources Coalition), which analyzed 70 studies, published from 2001 to 2015, on "the Open Access citation advantage." Of these, nearly twice as many studies (46) found an OA citation advantage as those that either found no citation advantage (17) or were inconclusive (7). ${ }^{21}$ Of course, averages across 
all fields and all modes of OA provide little value to an author making a personal decision about where to publish.

Where author perspectives on OA do appear in the scholarly literature, they tend to be negative and contain misinformation. Library researchers have identified such faculty concerns as "less trust in the personal benefits of open access" 22 and a "[belief] that OA is lower quality." ${ }^{23}$ Recent pieces from the perspectives of ecology and wildlife science indicate strong opinions of OA that are rife with suspicion and outright hostility. An article in Trends in Plant Science warned of the negative implications of OA, including "little quality control, conflicts of interest [for publishers], and no stamp of rigor or potential impact." ${ }^{24} \mathrm{~A}$ Journal of Wildlife Management piece echoes concerns about quality while predicting that OA will dilute science and the unique contribution of scientific society journals. ${ }^{25}$ These examples support the conclusion that "misguided concerns and mistaken beliefs about OA still stand." ${ }^{26}$ These stances force librarian supporters of $\mathrm{OA}$ to defend against questionable assumptions about open publishing. Librarians also fight for relevance: a study of authors in a variety of disciplines found that OA status was only marginally significant and less so than journal scope or quality. ${ }^{27}$ As an important part of our study, we wanted to learn the particular concerns of local researchers so we could address them most effectively.

\section{Methods}

This study comprised two broad components: we analyzed the journal and author information derived from a Scopus report and then administered a survey to learn authors' personal motivations. Using Scopus institutional reports, we identified 256 USU-affiliated researchers who published an OA article in the 2016 calendar year. Scopus's indexing included only articles published in journals that were Gold OA (fully Open Access) and not Hybrid OA (subscription journals with the option to pay to make one's article Open Access). We compiled researcher names and used USU's directory and website to determine each author's tenure or student status and discipline. The list of publication venues as given in the Scopus data was analyzed using individual journal web pages, the Ulrichsweb Global Serials Directory, the Directory of Open Access Journals, and SHERPA/RoMEO to determine each publication's OA status and publicly listed APC. The authors converted APCs in other currencies to US dollars based on weighted averages of the monthly average rates from 2016 as listed on x-rates.com. We used the following multipliers to calculate USD equivalences from the original currency: CHF: 1.015270325, BRL: 0.288337648, GBP: 1.355688505, EUR: 1.106750981.

The second part of the project moved beyond these publicly visible factors with the goal of gaining a better sense of researcher motivations behind the choice to publish OA. To achieve this, we designed a survey and distributed it to the compiled list of researchers. (The survey instrument is included as appendix A). In cases where published articles included a survey instrument or sample questions, ${ }^{28}$ we drew loosely upon past research in developing our survey. However, the subject of our research question-OA authors instead of all faculty, only those affiliated with our institution, responding with regard to a particular published article from the past year-was generally unique enough to render others' questions not directly reusable. Using an institutional subscription to Qualtrics, we entered each author's email address to administer the survey. This allowed us to track who had responded without connecting the response to the particular respondent. We received responses from tenured faculty, tenure-track faculty, students, and (presented here as an aggregate "other" category) 
administrators, staff, and nontenure-track faculty (see figure 1). We collected survey responses from May 2017 to July 2017.

The survey questions addressed several issues that the authors surmised could be important driving factors behind choosing $\mathrm{OA}$. The first set inquired about department and status - whether participants were tenured or nontenured faculty, students, or staff. The next set of questions concerned what persons or groups (among peers, mentors, and promotion-and-tenure committees) influenced the authors' decision to publish OA, the general opinion of these parties about OA publishing, and whether or not respondents advise students to publish OA. The next set of questions concerned motivations and asked about the relative importance of OA status when selecting a publication venue as well as specific questions related to the choice to publish OA. Respondents selected all that applied from among the following: "Altruism or social responsibility," "Greater likelihood of being cited," "New avenues of impact via social media," "Suspicion of the for-profit model of large publishers," "Acceptance of OA by disciplinary peers," "Speed of editing and publishing process," and "Journal more relevant than non-OA options." The last set of questions was about the APCs charged and how the authors paid those fees, whether through the library's OA fund, grant funding, departmental funds, or personal funds.

\section{Results}

The authors sent the survey to 256 authors; 96 responses were received, of which 86 (33.6\% of the total) were complete and usable. Because the sample size is sufficiently large, we consider the results broadly representative of USU authors of OA articles and therefore generalizable to that population. However, although we can suggest areas for further research among authors outside our study population, we do not posit that these results represent either OA authors at any other institution or non-OA authors at our own.

\section{OA Authors by Tenure Status}

One hypothesis was that an author's tenure status would make her more or less likely to publish OA. Either established, tenured professors would not be afraid of publishing in OA journals stereotyped as poor quality, or younger, untenured professors would see the unique value proposition of OA, such as open sharing of peer-reviewed research via social media. According to our analysis of Scopus data, more than twice (2.4 times) the number of tenured faculty (102, or $70 \%$ of faculty) published at least one OA article in 2016 as compared to tenure-track faculty (43, or $30 \%$ of faculty; see figure 1 ). The respective numbers align very closely with the number of faculty

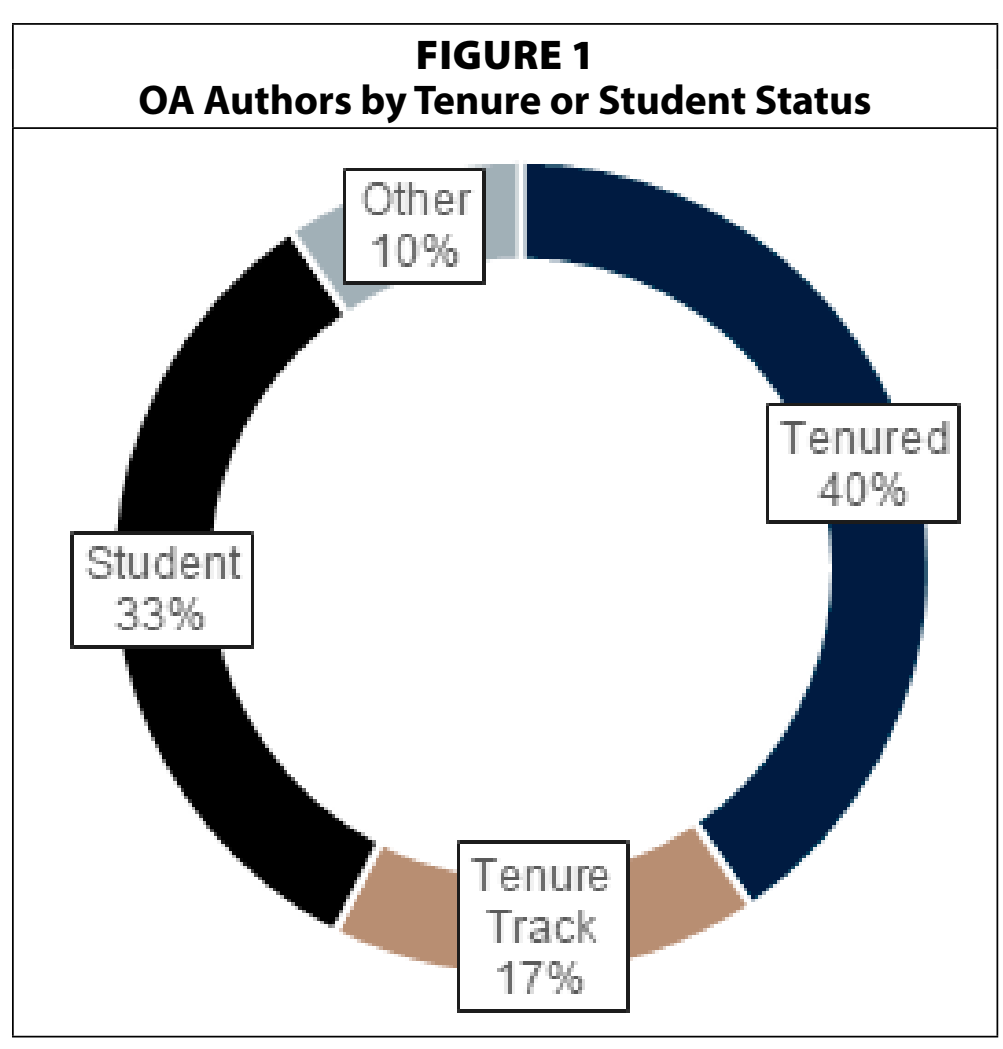


in each category at USU, where there are twice the number of associate and full professors (626) as assistant professors (330). Beyond these professors, who fulfilled our expectation of being strongly motivated to publish, a surprising one-third of our list of OA authors were students. Students' publication incentives and perceptions of OA may prove very different from those of faculty, but we do not systematically highlight student responses in this article.

\section{OA Authors by Discipline}

We wanted to know if an author's discipline made it more likely that she would publish OA, so we used USU college affiliations as an imperfect proxy for academic discipline. (See appendix B for a list of departments in each college.) We also excluded students from this part of our analysis to compare author counts to each college's total faculty employment. By analyzing the Scopus data, we found that disciplinary differences do seem likely to influence faculty authors' OA decisions. The highest raw numbers of OA authors (see figure 2) came from the Science (35), Natural Resources (30), and Education \& Human Services (23); the highest percentages of faculty in a college publishing OA came from Natural Resources (59\%), Science (24\%), and both Engineering (18\%) and our catchall "Research Centers, Extension, \& Other"

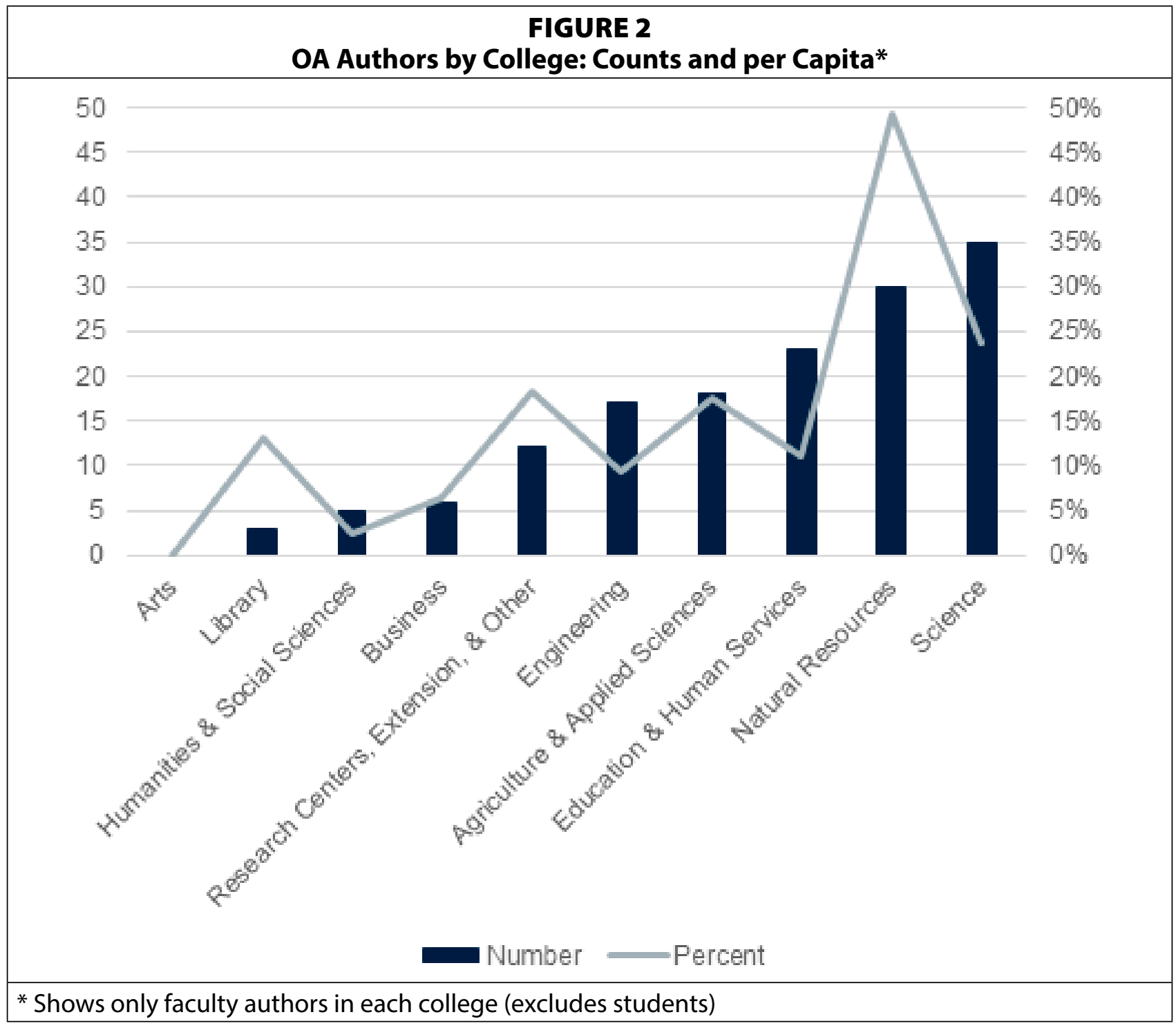


category $(18 \%)$. On a more personal note, the library was the next-highest per-capita "college" at 13 percent of faculty publishing $O A$. In all these cases, the percentage more clearly indicates disciplinary influences than do the raw counts.

\section{Awareness of Library OA Fund}

The USU Library boasts a thriving but modest OA fund to support authors' payment of APCs in gold OA journals. Conditions for the awards include a requirement that authors request matching funds from a department, college, or external funding source. Because the fund is easily depleted each year and some applicants are turned away, it is advertised only passively. Still, might an author's awareness of this fund make her more likely to appear in the list of OA authors? In our survey, we asked, "Are you aware of the Library's Open Access fund?" and included a link to the fund's information page. Nearly two-thirds $(60 \%)$ of respondents were aware of the fund. Because of the library's minimal efforts to promote the fund, we did not expect this level of awareness even among authors of OA articles. On the other hand, a substantial portion ( $40 \%$ ) of USU researchers has pursued OA publishing even without awareness of the library's support for the paradigm. Along with the total ratio of OA awareness among faculty, we also now know the degree to which knowledge of the fund has penetrated the various departments.

\section{Source of APC Payment}

Along with testing the university's knowledge of the library's OA fund, we wanted to know what kind of burden APCs placed on authors. If sufficiently onerous, these costs could deter authors from OA publishing. Obviously, our population consists of those not deterred, but the actual costs and fund sources might explain why. To answer this, we first collected the APC costs for each journal, as described in the methods section above. Of the 77 unique journals on our list, we were able to find an APC (on the journal site, in the DOAJ, or elsewhere) for $52(68 \%)$. This left 25 journals (32\%) that charged no APC or for which we could not find a charge listed. (This percentage is close to a 2014 estimate that fully OA journals that charge no APC publish 28 percent of OA articles..$^{29}$ ) Of the 52 journals that charged an APC, 44 (85\%) charged a single fee for the whole article, and $8(15 \%)$ charged their fees per page. Both types of fees, where not listed in USD, were converted as described in the methods section. The article-level APC mean was $\$ 1,514.36$; the median was $\$ 1,473.19$. The page-level APC mean was $\$ 70.18$; the median was $\$ 88.58$. These amounts correspond closely with analyses done by others. ${ }^{30}$ For those individuals seeking to publish an article in the 68 percent of journals that charged fees, we did consider these amounts substantial and likely barriers to choosing OA.

Fortunately, most authors in our study did not pay out-of-pocket the APCs associated with their articles. The survey asked, "What source(s) did you use to pay the Open Access fees [referred to in the previous question]?" Respondents selected all options that applied to any OA article they published in 2016. Only 7 respondents (5\%) chose "Personal funds" as one of their funding sources (see figure 3). The results confirmed our suspicion that grant money was often used to pay APCs, and it was the source used by the most respondents (34\%). The library OA fund came unexpectedly in second $(26 \%)$, followed by the author's college or department $(19 \%)$. The prevalence of college or department funds was particularly surprising because our OA fund application requires that authors request department or college funds (or grant funds), where available, to match the library's contribution, and often those matching funds 
are not forthcoming. ("Other" responses generally referred to being unsure about the payment source, often because a coauthor handled any APC payment.) Because 95 percent of our respondents either had access to funding or were not required to pay an APC, it seems highly likely that ability to pay was indeed a major contributing factor in our authors' OA decision.

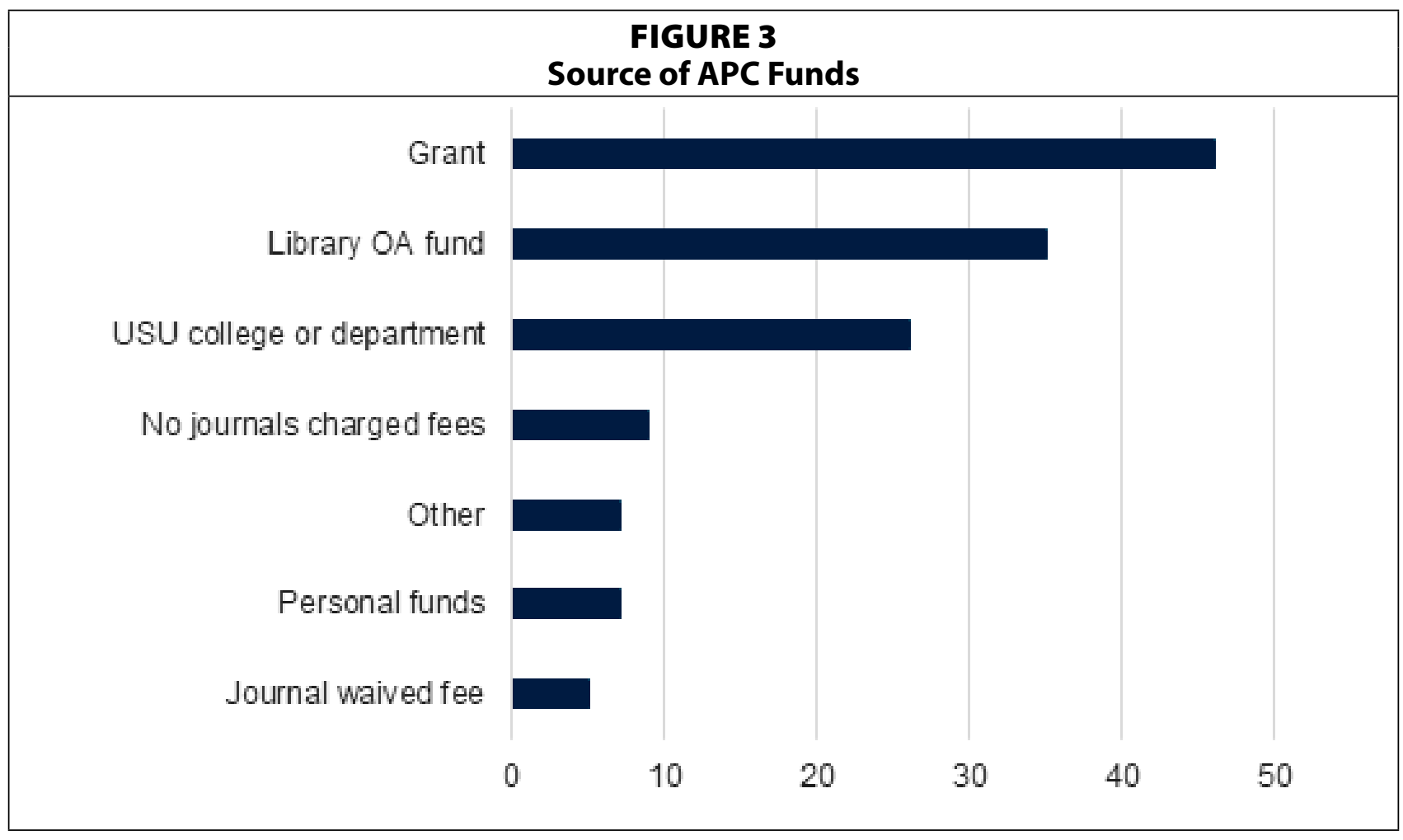

\section{Influence of Individuals and Groups on OA Decision}

All of the questions addressed above serve as possible motivating factors for authors: tenure status, discipline, and availability of funding. Along with these, we probed authors' motivations directly. Responses about the influence of research mentors, tenure committees, and peers in the decision to publish OA are shown in figures 4 through 10, and the relative weight of traditional factors and the unique value proposition of OA are shown in figures 11 and 12.

Direct questions about author motivations began with personal influences. Respondents were asked which individuals influenced their decision to publishing OA. Respondents selected all that applied among the options: "Promotion-and-tenure committee (for faculty) or faculty committee (for graduate students)," "Supervisor or research mentor," and "Peers at USU and elsewhere." As shown in figure 4, the 86 respondents were influenced toward OA most strongly by peers ( 48 respondents, or $56 \%$ ), with the direct supervisor of their research work having a much smaller influence $(23$, or $27 \%)$, and promotion-and-tenure committee having the smallest $(11$, or $13 \%)$.

After asking if others had any influence on authors' decisions, we asked whether those parties' opinions toward OA were positive or negative and how strong that influence was. Based on their responses to the above question, respondents were presented any or all of the below follow-up questions:

- "What was the general opinion of your promotion-and-tenure committee or faculty committee regarding Open Access publishing?" 
- "What was the general opinion of your supervisor or research mentor regarding Open Access publishing?"

- "What was the general opinion of your peers at USU and elsewhere regarding Open Access publishing?"

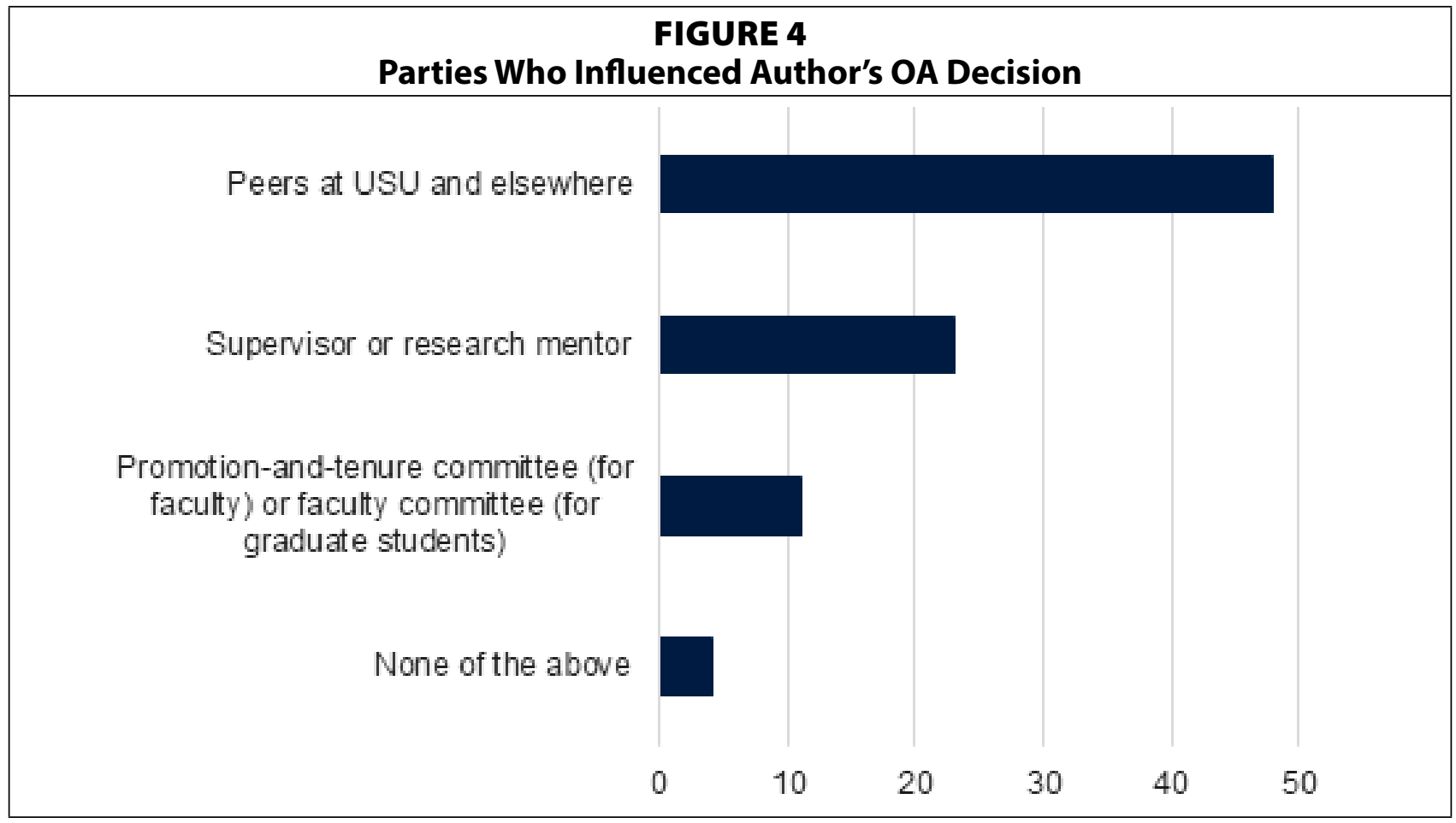

These questions were answered using a five-point Likert scale, from extremely or somewhat positive to somewhat or extremely negative, with "Neither positive nor negative" as a neutral response. Respondents then rated the significance of each selected party's influence on a five-point Likert scale, from extremely or very influential to slightly influential or not influential at all, with "Moderately influential" as the neutral response.

Peer influence was not only cited as influential most often (48 respondents), but it was also by far the most positive (see figure 4). As gauged by authors, peer OA opinions of "Extremely positive" and "Somewhat positive" represent 92 percent of those claiming to be influenced by such peers (see figure 5). This is challenged only by the 8 percent of respondents who stated that their peers' opinion of OA was "Neither positive nor negative." As shown in figure 6, peers were "Moderately influential" 46 percent of the time, "Extremely influential" or "Very influential" 31 percent of the time, and "Slightly influential" or "Not influential at all" 23 percent of the time. (Note that, in this series of questions, several chose "Not influential at all" even after previously selecting the respective party in response to the question "The opinion of which of the following, if any, played a role in your decision to publish Open Access?" Those responses are included in the counts given in figure 5.)

As already mentioned, supervisors or research mentors influenced considerably fewer respondents (23) to publish OA than did peers, but that influence was similarly positive toward OA. As shown in figure 7, their opinion was "Extremely positive" or "Somewhat positive" 87 percent of the time and "Neither positive nor negative" the remaining 13 percent. More interesting, those respondents whose supervisors or research mentors influenced them toward 


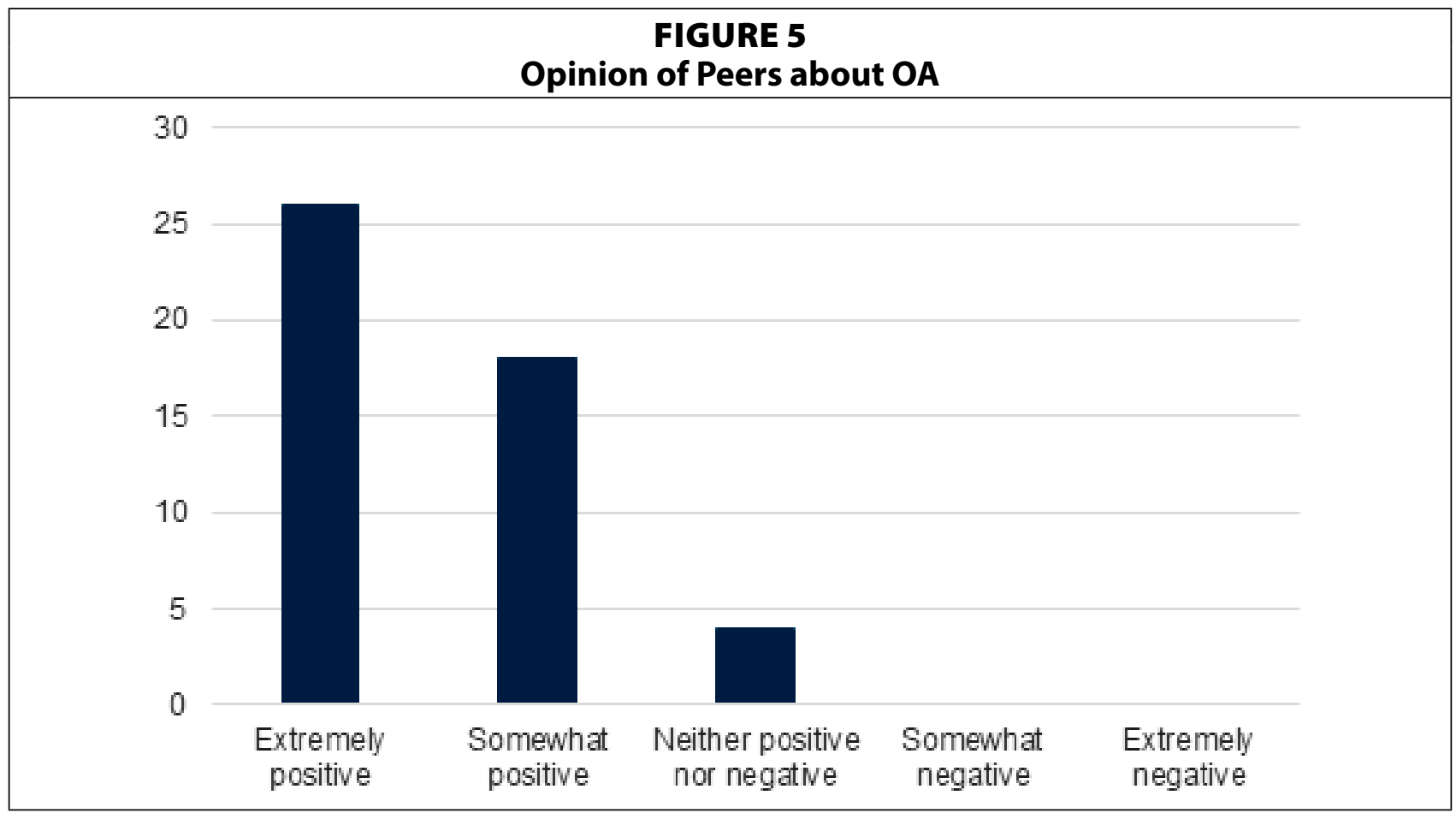

OA assigned stronger influence to them than respondents did to any other group. While figure 8 shows that, for some, supervisor influence was minimal (17\% "Slightly influential" or "Not influential at all"), the largest category was "Very influential," on its own representing 30 percent of those who claimed any supervisor influence. Of these, 57 percent overall stated that their supervisors were "Extremely influential" or "Very influential," and 26 percent stated that they were "Moderately influential" in their decision to publish OA.

Promotion-and-tenure committees were the final and surprisingly least influential group among our authors (selected by only 11 respondents, 10 of whom answered the subsequent

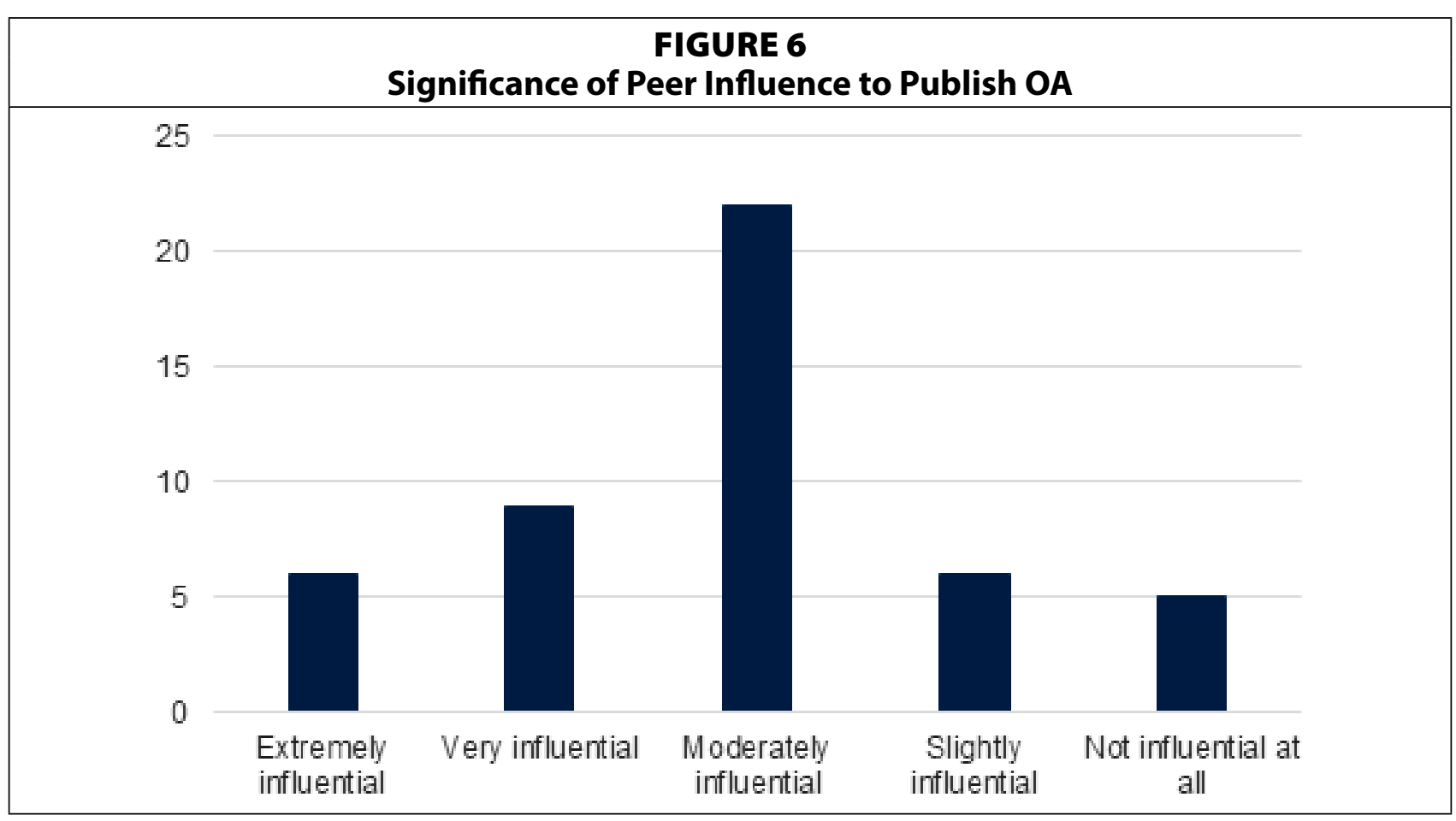




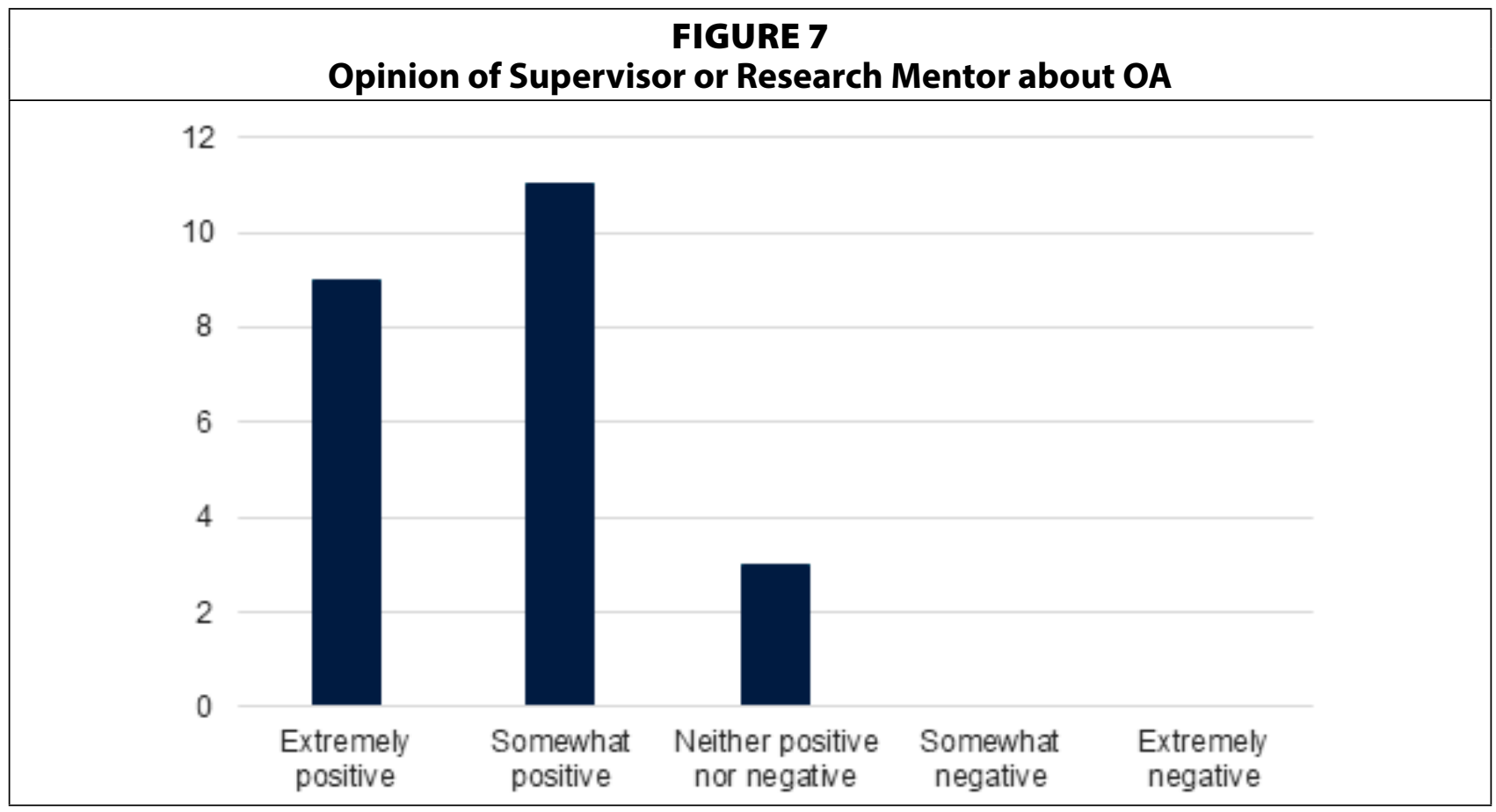

questions on the magnitude of that group's influence). As with the other groups, their opinion was overwhelmingly positive: 80 percent of respondents saw their tenure committee's opinion of OA as "Extremely positive" or "Somewhat positive," with the remaining 20 percent "Neither positive nor negative" (see figure 9). However, 30 percent of these respondents claimed that their tenure committee was either only "Slightly influential" or "Not influential at all" (figure 10). For another 40 percent, the committee was "Moderately influential," and the final 30 percent found it "Extremely influential" or "Very influential." The lukewarmth of these responses on significance of influence corroborates the low number of respondents that selected the tenure committee as an influence at all.

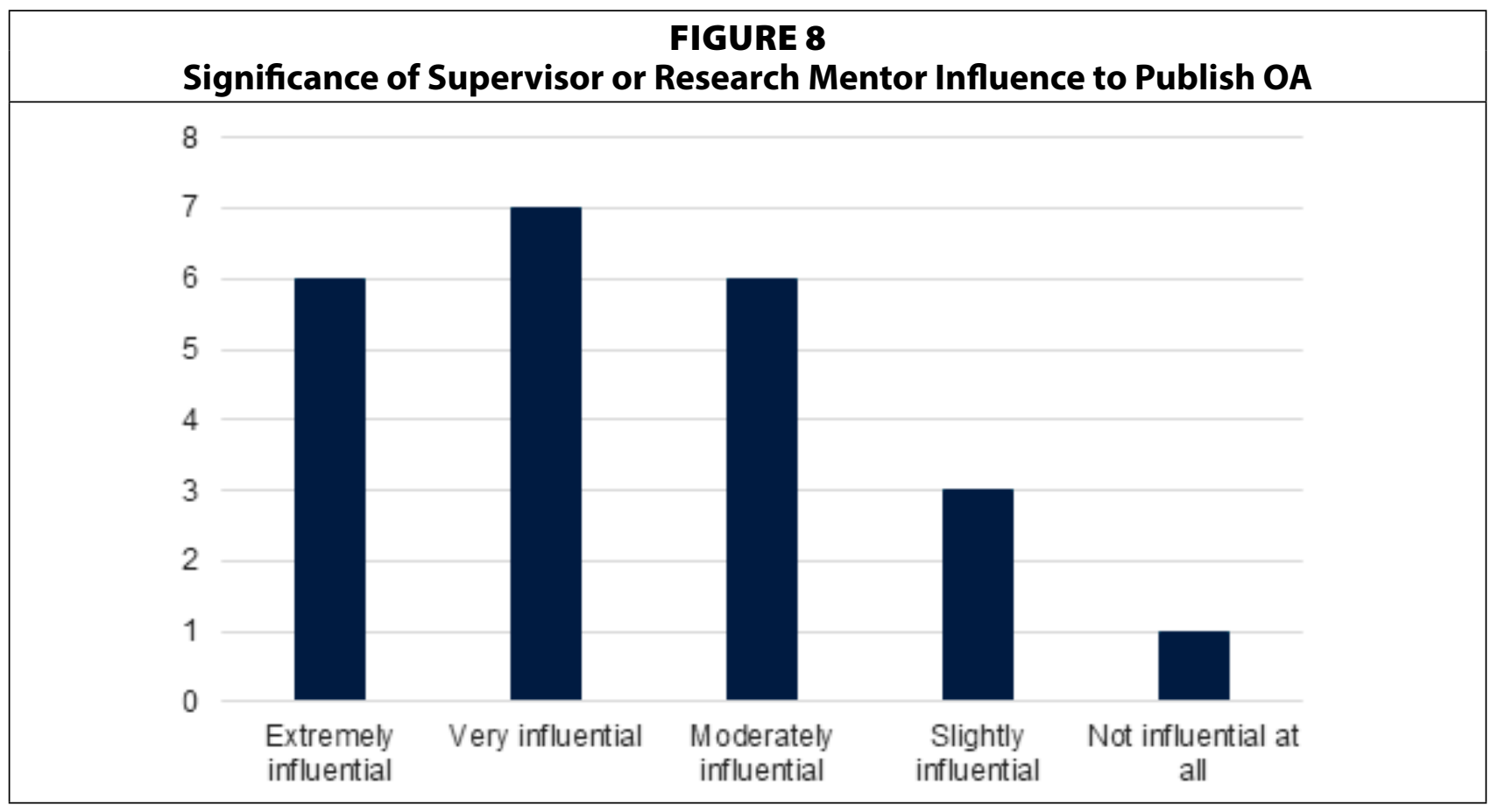




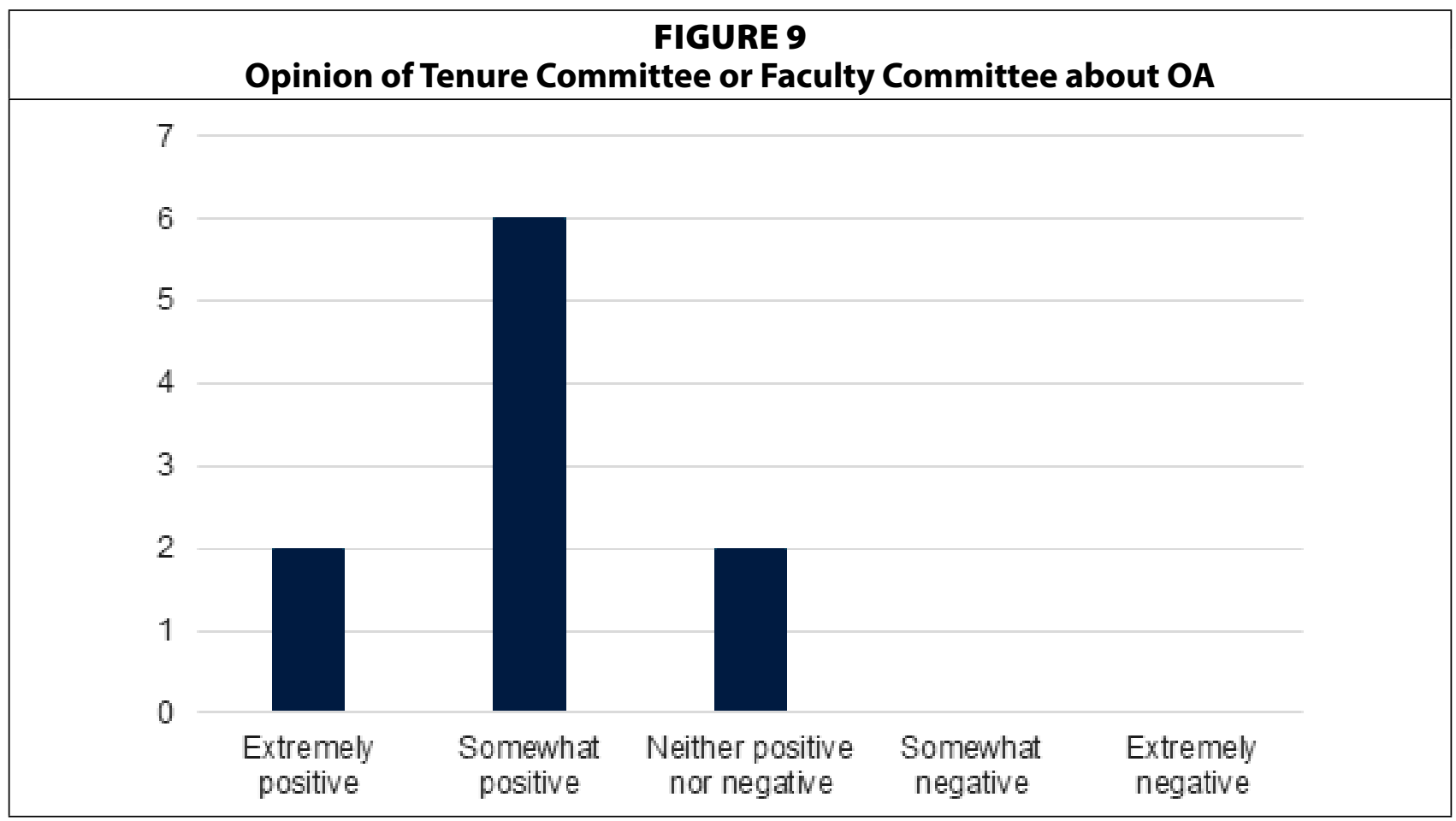

Importance of OA Status in Venue Choice

Our final lines of inquiry were about the factors, separate from the influence of individuals and groups, that personally motivated authors to choose OA venues for their articles. We introduced this section with the question "To what degree was Open Access status a factor in your choice of publication venue?" Responses (shown in figure 11) tended toward the center, with 34.5 percent "Moderately important," 30 percent "Extremely important" or "Very important," and 34.5 percent "Slightly important" or "Not at all important."

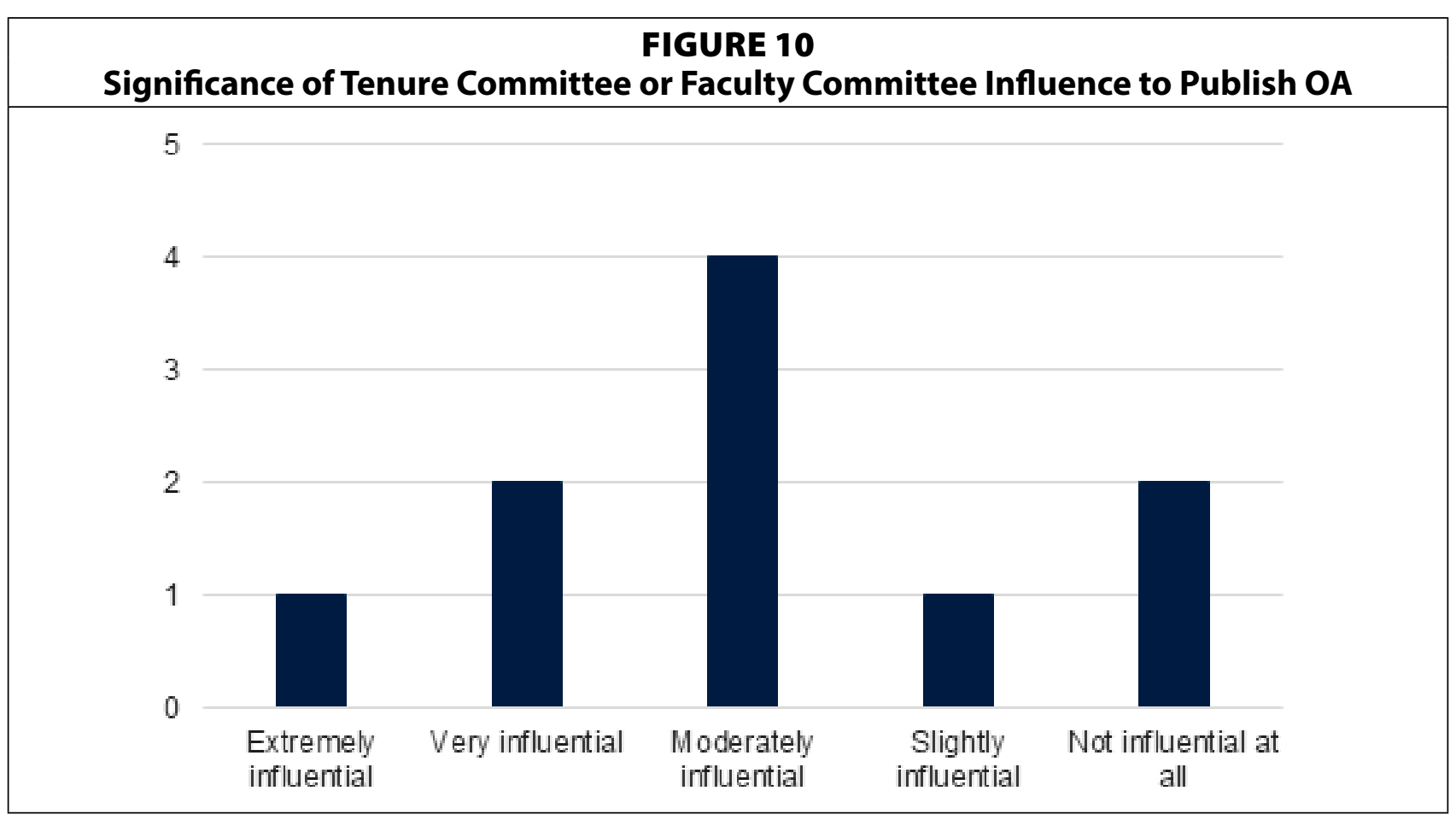




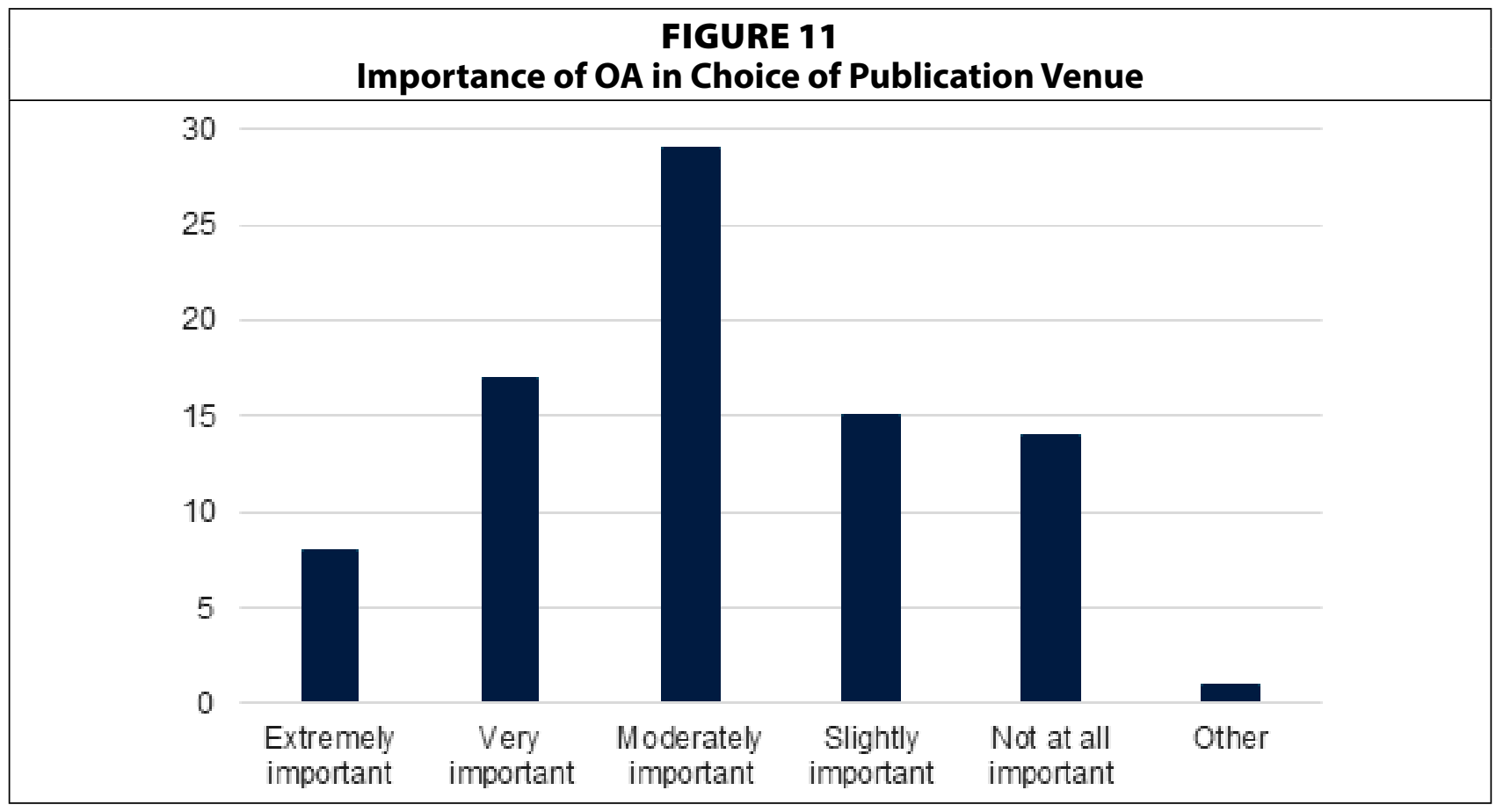

\section{Ideological Motivations toward $\mathrm{OA}$}

When directly questioned about their personal motivations for publishing OA, authors chose a wide range of factors. The question was phrased as "Which of the following factors influenced your decision to publish Open Access?" We predefined the options in the survey based on the literature, and most respondents ( $86 \%$ of 86 respondents to this question) were content to confine themselves to these responses. Exactly half $(50 \%)$ of respondents chose "Altruism, general sense of social responsibility" as a motivation (see figure 12), with 38 percent of

\begin{tabular}{|r|r|r|} 
FIGURE 12 \\
Factors in OA Decision \\
\hline Altruism, general sense of social \\
responsibility \\
Greater likelihood of being cited \\
Speed of editing and publishing process \\
better than non-Open Access journals \\
Acceptance of Open Access by \\
disciplinary peers
\end{tabular}


respondents choosing "Greater likelihood of being cited." From there, responses gradually drop to as low as 21 percent each for "Suspicion of the for-profit model of large publishers" and "New avenues of impact via social media." In selecting "Acceptance of Open Access by disciplinary peers," 36 percent of respondents confirmed findings from earlier in the survey, situating this at the middle of other influences.

We made an attempt to analyze responses to this question according to various subdivisions, such as OA versus traditional publishing or altruism versus self-interest. For example, we found it interesting that altruism and citation likelihood were the options chosen most while suspicion of publishers' profit motive and impact via social media were those chosen least. These four choices seem closest aligned with the OA movement, but their importance to respondents was highly variable. The lines between ideological groupings also proved elusive. For example, "Suspicion of the for-profit model of large publishers" might be aimed at retaining public access to the results of publicly funded research (an altruistic motive), or it might be motivated instead by protecting the author's own copyright permissions (a selfinterested motive). Features of traditional publishing such as speed of editing and relevance of the journal to the article made an appearance, but they did not predominate the responses. Future research might clarify the conceptual categories more discretely, but we recommend doing this only to the degree that such categories align with authors' mental models and therefore may influence their decisions.

Twelve respondents chose "Other" in conjunction with the listed responses. Many of the 12 included written responses that were variations on altruism or likelihood of citation, where we were not always able to detect the particular emphasis respondents were trying to make. For example: "Wider access for readers," "Accessible to people in developing nations," "Some collaborating institutions are in developing countries without access to expensive journals," and "Higher impact factor." One response mentioned, "Funding agencies expect it," highlighting a gap in the options included in the survey.

\section{Discussion}

The findings from our collected data have implications for local practice and suggest possible directions for future research.

Cost was an important factor in authors' decisions; in general, only those with the ability to pay APCs ended up on our list of OA authors. Respondents' comments made this explicit: "I have very limited money to publish so I publish where it is either free or minimal cost as much as possible," wrote one respondent. Another commented, "I have never published an article where I was responsible to pay the fee in an open access journal. I have collaborated with researchers that published their results in an open access journals [sic]." Another respondent said, "I like the concept [of OA] a lot but cannot afford it." It is important to note that no matter the feelings of openness and altruism in publishing their research, authors can be constrained by finances. Of course, this study did not gather evidence that USU researchers would publish OA in greater numbers if not for those constraints, but we might logically explore that angle in the future. Also regarding the financial aspect of OA publishing, we were surprised at the prevalence of funding from the authors' colleges or departments. If the library can open up communication more directly with colleges and departments to learn what value local administrators place on OA publishing, we may be able to extend the yearly viability of the library's OA fund by sharing costs more effectively. Future research elsewhere may reveal more about 
the nature of grant funding as it relates to publishing research results. For example, do grants often include APCs as a line item, or are publication costs represented more generally? There is also room for better understanding of those who pay out-of-pocket. Such authors should be a high priority for marketing and education efforts for the library's OA fund.

Tenure status, another factor we suspected would be influential in the OA decision, did not correlate with any particular sentiment toward OA. Proportionate numbers of tenuretrack and tenured faculty published OA in the population we studied. While no respondent reported a strong negative bias against $\mathrm{OA}$ from their committees or supervisors, the data do not strongly indicate overall enthusiasm about OA from tenure and promotion committees. In fact, only one faculty member, a tenured faculty member, felt that promotion was "very influential" in his or her decision to publish OA; other reasons, including altruism, speed of editing, and citation potential were weighted more significantly in faculty minds than the opinions of promotion committees. Much work can be done to expand the literature on faculty motivations to publish, both in general and in OA venues in particular. What different pressures to publish operate on junior and senior faculty (in other words, on those seeking only promotion compared to those seeking tenure)? One difficulty in seeking global answers to such questions is that "the tenure system" is more multitudinous than monolithic. There may not be sufficient consistency in tenure requirements across institutions - or even concreteness of expectations at an individual institution - to make comparisons meaningful. However, tenure incentives almost certainly influence authors' choices about publishing, and understanding these economics might direct future initiatives to encourage OA publishing.

As the literature showed, despite inconsistencies, disciplines do seem to be a primary influencer on authors regarding OA publishing. Those effects can be significant, as we saw in the fact that 50 percent of faculty in our College of Natural Resources published OA (see figure 2). This represents a broad field; but, ideally, we can apply lessons from natural resources to other areas. Does their field have a higher number of prominent OA journals than other fields? Have their professional associations sponsored OA journals where other fields' associations have not? It is equally possible that faculty in natural resources experience conditions that make them unique, keeping us from applying to other disciplines any insights gained. Perhaps local rather than disciplinewide conditions have led to this result. In any case, we will continue to explore the causes of disciplinary trends at USU, and researchers elsewhere can confirm or refute the global-level support of various disciplines for OA.

Our study brought significantly more clarity to the question of personal influences toward or away from OA. We were surprised to learn that, more than supervisors or tenure committees, peers had the strongest influence on authors. More than 50 percent of respondents claimed that peers influenced them toward OA publishing. Authors perceived peer attitudes toward OA, like those of supervisors and tenure-committee members, as overwhelmingly positive. Again, the blind spot in our vision is whether non-OA authors perceived similar opinions in their peers but had other motivations to choose non-OA venues. Also, how were these perceptions conveyed to authors? Is that influence explicit or implicit? Do peers have greater influence for early-career researchers than for those with tenure? And, again, is the nature of this influence generally confined to a department's culture at a particular institution, or can similar trends be seen in wider groups?

We conducted this study to move beyond our own perspectives, and we learned a great deal from the personal, intangible factors that motivate USU authors to publish OA. Most 
surprising was a clear lack of buy-in to many principles of the open-publishing agenda. For example, the motivating factors "Suspicion of the for-profit model of large publishers" and "New avenues of impact via social media" were those selected least often. The free-response comments were particularly illuminating for the question, "Which of the following factors influenced your decision to publish Open Access?" One respondent wrote: "[I a]void publishing in too many non-selective OA journals (Plos One, PeerJ) at early career stage because the old guard views those publications negatively. But, there are plenty of society journals that have OA options now." Another wrote, despite having published OA him- or herself, "I strongly dislike open access journals as a direct source to target for publication," and the same respondent later commented that "open access journals often seem predatory ... and [I] advise my students to avoid them." A single respondent stated that OA status "is Extremely important, but as a deterrant [sic] for publishing." Such responses cast doubt on a key assumption about our population, namely that $\mathrm{OA}$ authors are OA advocates.

However, we did see many indications of our authors' support for OA. As shown in figure 11 , around 83 percent of respondents ascribed some importance to the journal's OA nature as a motivation for their choice, and respondents selected altruism more than any other motivating factor. One author said, "I was mostly influenced by overseas colleagues and the ability of my research to be easily accessed by those not affiliated with U.S. research institutions that have easier access to traditional publications. Additionally, I like the ideas [sic] of not giving my precious research/grant dollars to large publishing houses." Another explained, "I think science itself should be open, and ... [the results of] publicly-funded science should be available to the public" as well as "accessible to people in developing nations." The diversity of comments show an engagement beyond a simplistic "publish or perish" worldview. A positive attitude toward OA may be more important in guiding authors' actions than whether that attitude derives from a moral conviction of OA as a public good or a belief that it serves the author's interests. ${ }^{31}$ The literature would benefit from a coherent framework of OA-related values that can link to different shareholders' perspectives, whether altruism or self-interest is a stronger motivator.

\section{Conclusion}

Publishing, open or not, is interconnected with the civic purposes of the university under the rubric of "academic citizenship." Macfarlane defines this concept as service to several distinct yet interrelated communities from the researcher perspective, including "students, colleagues, their institution, their discipline or profession, and the public." ${ }^{32}$ If the university values citizenship, promoting OA publishing is a way to encourage the reach of its research, in effect enlisting publishing as a form of service (though clearly distinct from the "service" responsibilities in faculty tenure requirements). Through the altruistic community outreach of OA publishing, the values of the university align with the values of some academic disciplines. We found that such disciplines as science and natural resources that have long traditions of valuing open science were in fact the most likely to publish OA in 2016 (see figure 2). However, in addition to the complex interactions that we discovered among discipline, tenure status, and other factors, the lack of consensus on approaches to OA means we are not likely to identify a single best way for universities to engage their communities, both local and global. 
Our research also highlights the tension between theoretical and practical considerations in advocacy for OA. We studied our departments' faculty and students as if their feelings and practices developed in isolation from library work. In reality, the strengths and weaknesses of OA's proliferation on our campus could result from uneven contact between our subject librarian program and the academic departments. Disciplines have different needs; librarians have different workloads and attitudes. For good and ill, faculty personalities in the library and in the departments generally determine the reception of our programs more than the value inherent to them. Unfortunately, efforts to assess subject librarianship at USU have been inconsistent. We cannot state with certainty which individuals on campus have received the library's various messages about OA publishing, let alone the more meaningful data on how they responded. The library recently hired a specialist in assessment, and assessing the impact of our liaison work in a deep, comprehensive, consistent way will be a high priority for her work. We are careful to consider our current findings in light of the underlying human relationships in order to plan for the library's role in the future of publishing.

While studies and op-eds on the future and potential of OA tend to paint research populations with broad brushstrokes, author motivations are multifaceted and complex. It is essential that librarians and the scholarly publishing community be aware of the multitude of reasons why faculty members choose OA outlets for their work. We found promotion and tenure unlikely to motivate USU authors toward OA while self-reported altruism reigned supreme. On the other hand, researchers still valued speed of editing and potential for increased citation and impact nearly as much. Though we may assume that the desire for promotion most strongly motivated faculty-publishing decisions, the results of our survey show that faculty are engaged in the scholarly debates surrounding capitalism, access, subscription models, and bad actors in scholarly communication. We also noted that their engagement may have a very different nature and motivation from our own. If we are to help them meet their goals in publishing their work, it will be through conversation rather than blind assumptions. 


\section{APPENDIX A. Survey Instrument \\ Open Access Publishing}

Q1 Please fully review this Letter of Information document before deciding whether to proceed with this survey. [letter of information displayed below; select one]

Yes, I agree to participate in this study

No, I do not agree to participate in this study

Q2 Thank you for your interest in our study. Please refer to our contact information in the email you received if you decide to participate. [displayed only if "No" was selected in Q1]

Q3 Which department represents your primary affiliation with USU? [the departments listed in Appendix B were presented in a drop-down menu]

Q4 If your main affiliation is not included in the above list, please explain.

Q5 What is your status as a faculty or student? [presented as a drop-down menu]

\section{Tenured faculty}

Tenure-track faculty

Non-tenure-track (incl. staff, adjunct, and so forth)

Graduate student

Undergraduate student

Q6 The opinion of which of the following, if any, played a role in your decision to publish Open Access? [select one]

Promotion-and-tenure committee (for faculty) or faculty committee (for graduate students) Supervisor or research mentor

Peers at USU and elsewhere

Q7 What was the general opinion of your promotion-and-tenure committee or faculty committee regarding Open Access publishing? [displayed only if this party was selected in Q6; select one]

Extremely positive

Somewhat positive

Neither positive nor negative

Somewhat negative

Extremely negative

Q8 How significant was the opinion of your promotion-and-tenure committee or faculty committee in your decision to publish Open Access? [displayed only if this party was selected in Q6; select one] 
Extremely influential

Very influential

Moderately influential

Slightly influential

Not influential at all

Q9 What was the general opinion of your supervisor or research mentor regarding Open Access publishing? [displayed only if this party was selected in Q6; select one]

Extremely positive

Somewhat positive

Neither positive nor negative

Somewhat negative

Extremely negative

Q10 How significant was the opinion of your supervisor or research mentor in your decision to publish Open Access? [displayed only if this party was selected in Q6; select one]

Extremely influential

Very influential

Moderately influential

Slightly influential

Not influential at all

Q11 What was the general opinion of your peers at USU and elsewhere regarding Open Access publishing? [displayed only if this party was selected in Q6; select one]

Extremely positive

Somewhat positive

Neither positive nor negative

Somewhat negative

Extremely negative

Q12 How significant was the opinion of your peers at USU and elsewhere in your decision to publish Open Access? [displayed only if this party was selected in Q6; select one]

Extremely influential

Very influential

Moderately influential

Slightly influential

Not influential at all

Q13 If applicable, how do you advise students regarding Open Access publishing? 
Q14 Give more details related to the previous responses if you would like.

Q15 To what degree was Open Access status a factor in your choice of publication venue? [select one]

Extremely important

Very important

Moderately important

Slightly important

Not at all important

Other (please explain)

Q16 Which of the following factors influenced your decision to publish Open Access? [select all that apply]

Altruism, general sense of social responsibility

Greater likelihood of being cited

New avenues of impact via social media

Suspicion of the for-profit model of large publishers

Acceptance of Open Access by disciplinary peers

Speed of editing and publishing process better than non-Open Access journals

Journal more relevant than non-Open Access journals to the article's content

Other

Other

Other

Q17 Did the journal(s) in which you published your article(s) require an Open Access fee (Article Processing Charge)? [select one]

Yes; all journals required fees or I published only one Open Access article

Some journals required fees; some did not

No journal(s) required fees

Q18 What source(s) did you use to pay the Open Access fees? [select all that apply]

Grant

Journal waived fee

Library Open Access fund

Personal funds

USU college or department

N/A (if answered "No" to previous question)

Other

Q19 Are you aware of the Library's Open Access fund? [select one]

Yes

No 
APPENDIX B.

List of Utah State University Departments by College

\begin{tabular}{|c|c|}
\hline College & Department \\
\hline \multirow[t]{5}{*}{ Agriculture \& Applied Sciences } & Animal, Dairy, \& Veterinary Sciences \\
\hline & Applied Economics \\
\hline & Landscape Architecture \& Environmental Planning \\
\hline & Nutrition, Dietetics, \& Food Sciences \\
\hline & Plants, Soils, \& Climate \\
\hline \multirow[t]{3}{*}{ Arts } & Art \& Design \\
\hline & Music \\
\hline & Theatre Arts \\
\hline \multirow[t]{4}{*}{ Business } & Accountancy \\
\hline & Economics \& Finance \\
\hline & Management \\
\hline & Management Information Systems \\
\hline \multirow[t]{8}{*}{ Education \& Human Services } & Communicative Disorders \& Deaf Education \\
\hline & Family, Consumer, \& Human Development \\
\hline & Instructional Technology \& Learning Sciences \\
\hline & Kinesiology \& Health Science \\
\hline & Nursing \& Health Professions \\
\hline & Psychology \\
\hline & Teacher Education \& Leadership \\
\hline & Special Education \& Rehabilitation \\
\hline \multirow[t]{6}{*}{ Engineering } & Biological Engineering \\
\hline & Civil \& Environmental Engineering \\
\hline & Computer Science \\
\hline & Electrical \& Computer Engineering \\
\hline & Engineering Education \\
\hline & Mechanical \& Aerospace Engineering \\
\hline \multirow[t]{6}{*}{ Humanities \& Social Sciences } & English \\
\hline & History \\
\hline & Journalism \& Communication \\
\hline & Languages, Philosophy, \& Communication Studies \\
\hline & Political Science \\
\hline & Sociology, Social Work, \& Anthropology \\
\hline Library & Library \\
\hline \multirow[t]{3}{*}{ Natural Resources } & Environment \& Society \\
\hline & Watershed Sciences \\
\hline & Wildland Resources \\
\hline
\end{tabular}




\begin{tabular}{|l|l|}
\hline \multirow{5}{*}{ Science } & Biology \\
\cline { 2 - 2 } & Chemistry \& Biochemistry \\
\cline { 2 - 2 } & Geology \\
\cline { 2 - 2 } & Mathematics \& Statistics \\
\cline { 2 - 2 } & Physics \\
\hline Research Centers, Extension, \& Other* & Center for Atmospheric \& Space Sciences \\
\cline { 2 - 2 } & Center for Persons with Disabilities \\
\cline { 2 - 2 } & Center for Women \& Gender \\
\cline { 2 - 2 } & Honors Program \\
\cline { 2 - 2 } & Office of Global Engagement \\
\cline { 2 - 2 } & University Extension \\
\cline { 2 - 2 } & Utah Public Radio \\
\cline { 2 - 2 } & Utah Water Research Laboratory \\
\hline
\end{tabular}

*This list includes only those entities represented in our list of faculty and does not include all research centers on campus.

\section{Notes}

1. SPARC, "Open Access," available online at https://sparcopen.org/open-access/ [accessed 22 May 2018].

2. "About SSP's The Scholarly Kitchen," The Scholarly Kitchen, available online at https://scholarlykitchen.sspnet. org/about/ [accessed 26 March 2018].

3. Gerald Beasley, "Article Processing Charges: A New Route to Open Access?" Information Services \& Use 36, no. 3/4 (2016): 163-70; Gail McMillan, Leslie O'Brien, and Philip Young, SPEC Kit 353: Funding Article Processing Charges (Washington, DC: Association of Research Libraries, 2016); Bo-Christer Björk and David Solomon, "Article Processing Charges in OA Journals: Relationship Between Price and Quality," Scientometrics 103, no. 2 (2015): 373-85, doi:10.1007/s11192-015-1556-z; Jane Monson, Wendy Highby, and Bette Rathe, "Library Involvement in Faculty Publication Funds," College and Undergraduate Libraries 21, no. 3/4 (2014): 308-29, doi:10.1080/106 91316.2014.933088.

4. Bo-Christer Björk and David Solomon, "How Research Funders Can Finance APCs in Full OA and Hybrid Journals," Learned Publishing 27, no. 2 (2014): 93-103, doi:10.1087/20140203; Frank Mueller-Langer and Richard Watt, "How Many More Cites Is a \$3,000 Open Access Fee Buying You? Empirical Evidence from a Natural Experiment," Economic Inquiry 56, no. 2 (2018): 931-954, doi:10.1111/ecin.12545; Stephen Pinfield, Jennifer Salter, and Peter Bath, "The 'Total Cost of Publication' in a Hybrid Open-Access Environment: Institutional Approaches to Funding Journal Article-Processing Charges in Combination with Subscriptions," Journal of the Association for Information Science and Technology 67, no. 7 (2016): 1751-66, doi:10.1002/asi.23446.

5. David Solomon and Bo-Christer Björk, "Publication Fees in Open Access Publishing: Sources of Funding and Factors Influencing Choice of Journal," Journal of the American Society for Information Science and Technology 63, no. 1 (2012): 98-107, doi:10.1002/asi.21660; Kate Lara, "The Library's Role in the Management and Funding of Open Access Publishing," Learned Publishing 29, no. 1 (2015): 4-8, doi: 10.1087/20150102; Pinfield, Salter, and Bath, "The 'Total Cost of Publication' in a Hybrid Open-Access Environment."

6. SPARC, "Open Access Funds in Action," available online at https://sparcopen.org/wp-content/uploads/2015/11/OA-Funds-in-Action_Nov-11-17.pdf [accessed 26 March 2018].

7. Monson, Highby, and Rathe, "Library Involvement in Faculty Publication Funds."

8. Björk and Solomon, "How Research Funders Can Finance APCs in Full OA and Hybrid Journals," 95.

9. Jere Odell, Kristi Palmer, and Emily Dill, "Faculty Attitudes toward Open Access and Scholarly Communications: Disciplinary Differences on an Urban and Health Science Campus," Journal of Librarianship and Scholarly Communication 5, no. 1 (2017), 1-22, doi: 10.7710/2162-3309.2169.

10. Stefanie Warlick and KTL Vaughan, "Factors Influencing Publication Choice: Why Faculty Choose Open Access," Biomedical Digital Libraries 4, no. 1 (2007), doi:10.1186/1742-5581-4-1. 
11. Dagmara M. Weckowska, Nadine Levin, Sabina Leonelli, John Dupré, and David Castle, "Managing the Transition to Open Access Publishing: A Psychological Perspective," Prometheus 35, no. 1 (2017): 1-25, doi:10.10 80/08109028.2017.1408289.

12. Jerrell Coggburn and Stephen Neely, "Publish or Perish? Examining Academic Tenure Standards in Public Affairs and Administration Programs," Journal of Public Affairs Education 21, no. 2 (2015): 199-214, doi:10.1017/ S1049096516003036.

13. Flora Tien, "To What Degree Does the Desire for Promotion Motivate Faculty to Perform Research? Testing the Expectancy Theory," Research in Higher Education 41, no. 6 (2000): 723-52, doi:10.1023/A:1007020721531.

14. Flora Tien and Robert Blackburn, "Faculty Rank System, Research Motivation, and Faculty Research Productivity: Measure Refinement and Theory Testing," Journal of Higher Education 67, no. 1 (1996): 2-22, doi:10. 1080/00221546.1996.11780246.

15. Tien and Blackburn, "Faculty Rank System, Research Motivation, and Faculty Research Productivity," $2-22$.

16. Gunther Eysenbach, "Can Tweets Predict Citations? Metrics of Social Impact Based on Twitter and Correlation with Traditional Metrics of Scientific Impact," Journal of Medical Internet Research 13, no. 4 (2011), doi:10.2196/jmir.2012; Jason Priem, Heather A. Piwowar, and Bradley M. Hemminger, "Altmetrics in the Wild: Using Social Media to Explore Scholarly Impact" (uploaded March 20, 2012), available online at http://arxiv.org/ html/1203.4745v1 [accessed 26 March 2018].

17. Julia Rodriguez, "Awareness and Attitudes about Open Access Publishing: A Glance at Generational Differences," Journal of Academic Librarianship 40, no. 6 (2014): 604-10, doi:10.1016/j.acalib.2014.07.013.

18. Christian Barton and Mark Merolli, "It Is Time to Replace Publish or Perish with Get Visible or Vanish: Opportunities Where Digital and Social Media Can Reshape Knowledge Translation," British Journal of Sports Medicine (published online November 16, 2017), doi:10.1136/bjsports-2017-098367.

19. Barton and Merolli, “It Is Time to Replace Publish or Perish with Get Visible or Vanish," 1.

20. Nieli Langer, "The Fundamentals that Contribute to the Concept of 'Publish or Perish,"' Educational Gerontology 43, no. 9 (2017): 429-30, doi:10.1080/03601277.2017.1332859.

21. SPARC Europe, "The Open Access Citation Advantage Service," available online at https://sparceurope. org/what-we-do/open-access/sparc-europe-open-access-resources/open-access-citation-advantage-service-oaca/ [accessed 26 March 2018].

22. Odell, Palmer, and Dill, "Faculty Attitudes toward Open Access and Scholarly Communications," 13.

23. Carol Tenopir, Elizabeth Dalton, Lisa Christian, Misty Jones, Mark McCabe, MacKenzie Smith, and Allison Fish, "Imagining a Gold Open Access Future: Attitudes, Behaviors, and Funding Scenarios among Authors of Academic Scholarship," College \& Research Libraries 78, no. 16 (2017): 824-44, doi:10.5860/crl.78.6.824.

24. Anurag A. Agrawal, "Four More Reasons to Be Skeptical of Open-Access Publishing," Trends in Plant Science 19, no. 3 (2014): 133, doi:10.1016/j.tplants.2014.01.005.

25. Charles Romesburg, "How Publishing in Open Access Journals Threatens Science and What We Can Do About It," Journal of Wildlife Management 80, no. 7 (2016): 1145-51, doi:10.1002/jwmg.21111.

26. Rodriguez, "Awareness and Attitudes about Open Access Publishing: A Glance at Generational Differences," 608.

27. Solomon and Björk, "Publication Fees in Open Access Publishing: Sources of Funding and Factors Influencing Choice of Journal."

28. For example, Warlick and Vaughan, "Factors Influencing Publication Choice: Why Faculty Choose Open Access."

29. Michael Jubb, Stéphane Goldstein, Mayur Amin, Andrew Plume, Stephanie Oeben, M'Hamed Aisati, Stephen Pinfield, et al., Monitoring the Transition to Open Access: A Report for Universities UK Open Access Coordination Group (London, UK: Research Information Network, 2015), 39, available online at www.acu.ac.uk/ research-information-network/monitoring-transition-to-open-access [accessed 26 March 2018].

30. Björk and Solomon, "How Research Funders Can Finance APCs in Full OA and Hybrid Journals," 94, 99.

31. Weckowska et al., "Managing the Transition to Open Access Publishing: A Psychological Perspective," 13.

32. Bruce Macfarlane, "Defining and Rewarding Academic Citizenship: The Implications for University Promotions Policy," Journal of Higher Education Policy and Management 29, no. 3 (2007): 261-73, doi:10.1080/13600800701457863. 